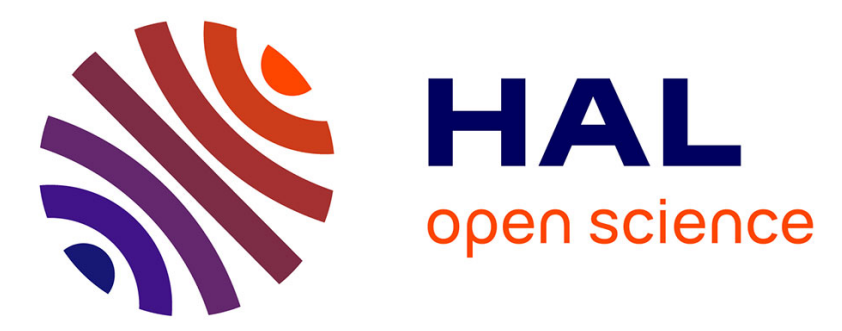

\title{
Development of the high-gradient electrostatic accelerator techniques in the Kyushu University tandem
}

\author{
A. Isoya, T. Kuroyanagi, Y. Nakajima, T. Nakashima, T. Maki, N. Kato, T. \\ Sugimitsu, K. Kimura, S. Mitarai, K. Kobayashi
}

\section{- To cite this version:}

A. Isoya, T. Kuroyanagi, Y. Nakajima, T. Nakashima, T. Maki, et al.. Development of the highgradient electrostatic accelerator techniques in the Kyushu University tandem. Revue de Physique Appliquée, 1977, 12 (10), pp.1315-1320. 10.1051/rphysap:0197700120100131500 . jpa-00244314

\section{HAL Id: jpa-00244314 https://hal.science/jpa-00244314}

Submitted on 1 Jan 1977

HAL is a multi-disciplinary open access archive for the deposit and dissemination of scientific research documents, whether they are published or not. The documents may come from teaching and research institutions in France or abroad, or from public or private research centers.
L'archive ouverte pluridisciplinaire HAL, est destinée au dépôt et à la diffusion de documents scientifiques de niveau recherche, publiés ou non, émanant des établissements d'enseignement et de recherche français ou étrangers, des laboratoires publics ou privés. 


\title{
DEVELOPMENT OF THE HIGH-GRADIENT ELECTROSTATIC ACCELERATOR TECHNIQUES IN THE KYUSHU UNIVERSITY TANDEM
}

\author{
A. ISOYA, T. KUROYANAGI, Y. NAKAJIMA, T. NAKASHIMA, T. MAKI, \\ N. KATO, T. SUGIMITSU, K. KIMURA, S. MITARAI and K. KOBAYASHI
}

Department of Physics, Faculty of Science, Kyushu University, Hakozaki, Fukuoka, 812 Japan

\begin{abstract}
Résumé. - A l'université de Kyushu un accélérateur tandem de 10 MV vient d'être terminé et se trouve en cours d'essai pour l'ensemble de ses performances. La construction de cette machine a commencé il y a cinq années et le principe de sa conception a été présenté à la conférence sur les accélérateurs électrostatiques à Daresbury [1]. Cette installation ne peut pas être considérée comme grande selon l'échelle standard, mais doit plutôt être appelé compacte. Cependant, les gradients de champ radial et axial de cette machine sont plutôt élevés à $10 \mathrm{MV}$, de sorte que la conception a été nécessairement faite avec l'intention de surmonter les différents problèmes dans des conditions d'un champ électrique élevé.
\end{abstract}

Abstract. - At Kyushu university a $10 \mathrm{MV}$ tandem accelerator is just completed and being tested for the overall performance. The construction of this machine was started five years ago and the design principle has been shown at the electrostatic accelerator conference at Daresbury [1]. This facility cannot be said to be large from the present standard but be called compact. However, radial and axial field gradients of this machine are fairly high at $10 \mathrm{MV}$ so that the design was necessarily made with an intention of overcoming various problems in the conditions of high gradient field.

1. Mechanical design feature. - Figure 1 shows the mechanical and electrostatic structure of this tandem. The inside diameter of the tank is $3.8 \mathrm{~m}$ and the length of each column is $5.3 \mathrm{~m}$. This size is nearly the same as that of the FN tandem. The column is divided into five sections with separating plates and a diagonal insulating post member is placed on center in each section. Arrangement of the horizontal and diagonal posts in the cross section of the column is shown in figure 2. Pellet chains and an accelerator tube are placed at both sides of the diagonal post. This arrangement allows the pellet chains and the tube wide space.
The tube is isolated from the column structure and independent dividing resistor chains are used for the column and the tube. The horizontal posts are tightly bolted to the separating plates in each section. In order to enable this sort of construction all the structual components of the column were produced with a very high precision.

The length of the diagonal members are made to be adjustable in order to eliminate the bending stress of the horizontal posts. This adjustment was made in every times when the load of the column was added during the construction. The axial compression force by the compression spring was also adjusted as the

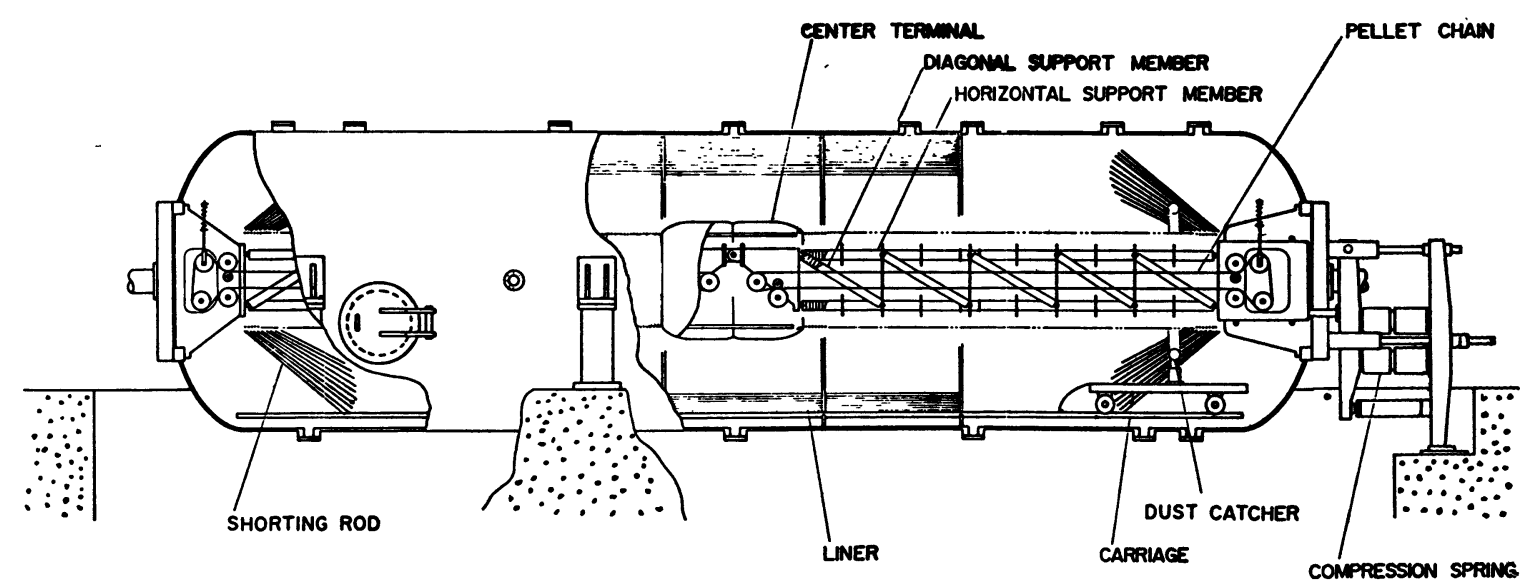

FIG. 1. - Basic mechanical and electrostatic structure of the $10 \mathrm{MV}$ tandem of Kyushu University. 


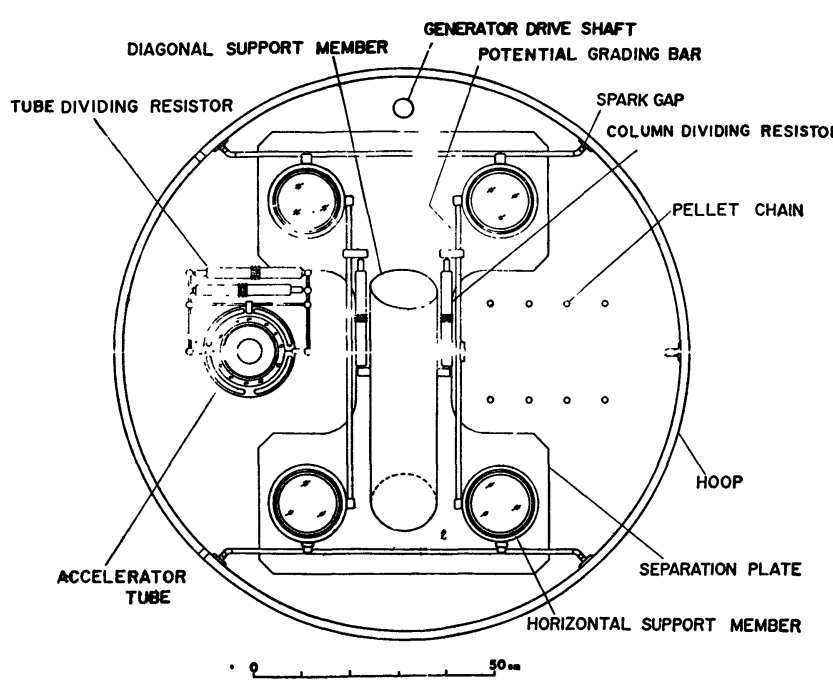

FIG. 2. - Cross section of the column. One diagonal member is set on the center, and an accelerator tube and four pellet chains are set at both sides of the diagonal member. Separate dividing resistors are used for the accelerator tube and the column.

load was changed so that in any support posts no tensile force occurred.

2. Electrostatic design feature. - About the electrostatic design feature, there are several points to be mentioned. First the shape of the high voltage terminal electrode and that of the hoops at the highest voltage sections are adjusted such that the field strength multiplication by the edge effect becomes minimum. The strength of the gross field on the terminal surface is $150 \mathrm{kV} / \mathrm{cm}$ at $10 \mathrm{MV}$ and the highest field strength as the result of the above optimization is $190 \mathrm{kV} / \mathrm{cm}$. For realizing this value, the shape of the hoop cross section is made elliptic. Secondly, $\mathrm{pure} \mathrm{SF}_{6}$ of $10 \mathrm{~kg} / \mathrm{cm}^{2}$ is used for the insulation gas. The theoretical breakdown strength of $\mathrm{SF}_{6}$ at this pressure is $860 \mathrm{kV} / \mathrm{cm}$. However, it reduces to about one half owing to the area effect. Hence the dielectric strength above mentioned keeps only the margin of a factor of two. This safety factor is not necessarily large since it may be easily lost if some small conductive dust attaches onto the critical portions of the electrode surface. Therefore, elimination of the dust from the inside of the tank becomes an urgent problem for generating a voltage of $10 \mathrm{MV}$ at our tandem.

The inner wall of the tank is covered in the central portion with a liner, which is made of pipes arranged in parallel with a spacing. Although the primary usage of this liner is to stabilize the terminal voltage by means of electrostatic feedback, it has a useful effect of masking dust existing on the tank wall from the high electric field.

3. A standard procedure for eliminating dust from the tank inside. - Elimination of the dust is a quite tedious task but its effect is very large. A standard procedure which is now taken is as follows : The first step is to sweep an air jet from a small nozzle over all objects and corners in the tank to blow out the dust and carry away with a flow of clean air which is sent into the tank by a blower with a microfilter. The speed of the wind of air should be large compared to a falling speed of the dust to be eliminated. This procedure has to be repeated many times. The degree of cleanness attained can be most effectively checked by generating a high voltage on the terminal under the normal atmospheric condition, using the pellet chains. If a clean condition is achieved, the terminal voltage can be raised up to a some maximum value, which is determined by a well-known theoretical breakdown field strength of $30 \mathrm{kV} / \mathrm{cm}$.

Usually sparks start to occur at about a half of this voltage. Then we take the second step of shaking off the dust by sparks. This is effectively done by putting a spark ring, surrounding the column, as shown in

\section{CORRESPONDING TERMINAL VOLTAGE OF TANDEM}
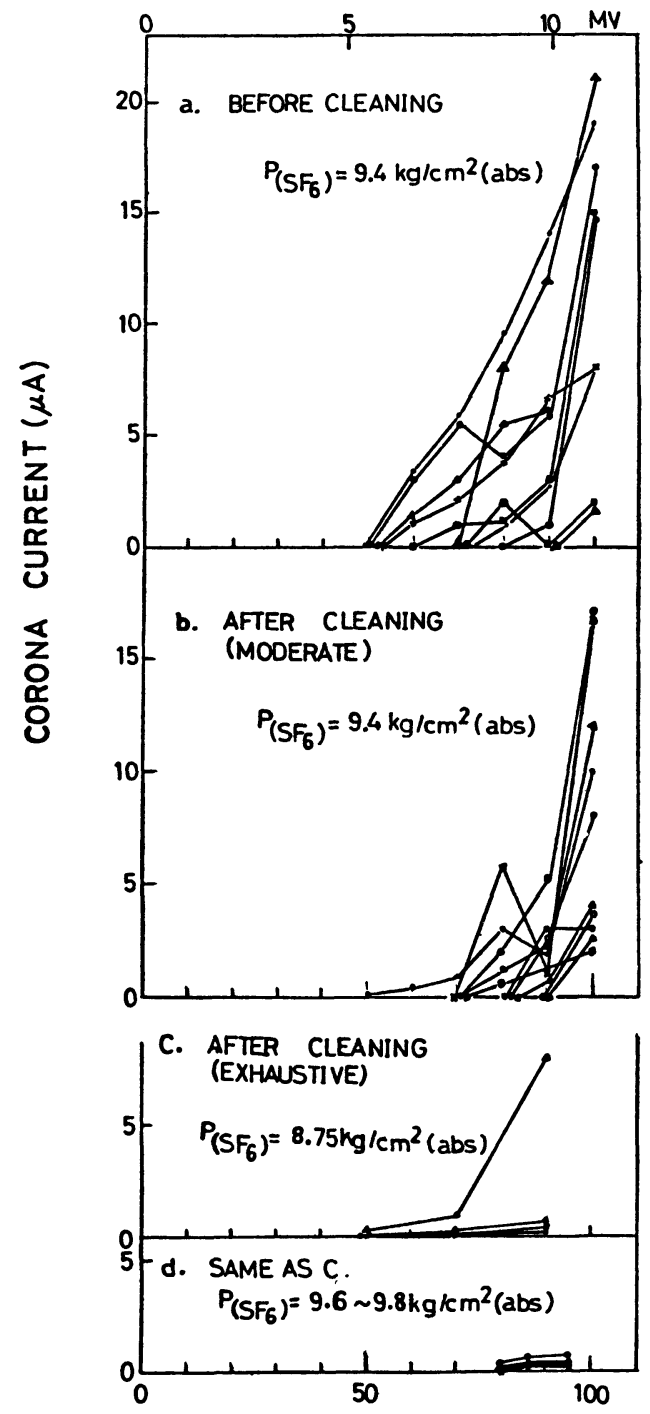

\section{VOLTAGE BETWEEN THE HOOPS (kV)}

FIG. 3. - Corona current flowing between the gaps of adjacent hoops under the different degrees of cleanness and the different pressures of $\mathrm{SF}_{6}$ insulation gas. 
figure 1 and inducing a large number of sparks between the spark ring and the hoops or the center terminal electrode. We call this ring a dust catcher. The dust catcher is mounted on a carriage and can be moved back and forth with generating a high voltage on the terminal. Dust is carried away with the spark ring. By this procedure the outer surfaces of the column electrodes can be conditioned without the risk of giving a damage to the column and finally the terminal voltage reaches 1.1 to $1.2 \mathrm{MV}$. In this case the voltage is limited only by the breakdown of the protecting spark gaps of the column. When this cleaning procedure was put in practice, the terminal voltage could be raised up to $11 \mathrm{MV}$ easily with $\mathrm{SF}_{6}$ of $10 \mathrm{~kg} / \mathrm{cm}^{2}$. No trial to get a higher voltage has been made.

Figure 3 shows a result of experiments which were carried out to see the possible magnitude of corona current occurring along the column axis at the highest voltage condition. Voltage was applied only to a single gap between the adjacent hoops in some column section and this voltage was moved over all the gaps of that section. It was found that the magnitude of corona current depends strongly on the degree of cleanness. This data indicated also that the corona suppression effect of $\mathrm{SF}_{6}$ gas does not saturate even at $10 \mathrm{~kg} / \mathrm{cm}^{2}$.

4. Protection of the components from the surges and the divíding resistors. - The next important provisions to be considered in the high voltage accelerators are the surge protection for the insulators or high resistance elements. In our tandem all the components requiring the protection (i.e. the column support posts, the accelerator tube, the dividing resistors, and the pellet chains) take a form of cylindrical configuration so that they can be most effectively protected by means of annular spark gaps.

Figure 4 shows a protecting spark gap, provided for the $1000 \mathrm{M} \Omega$ resistor, which is used as a standard unit in both the column and tube resistors. This type protection system was first used in the $6 \mathrm{MV}$ Vande-Graaff in our laboratory [2]. Before, damage of the resistors was the most frequent cause of trouble. But after the above type of protection system was adopted, it disappeared completely.

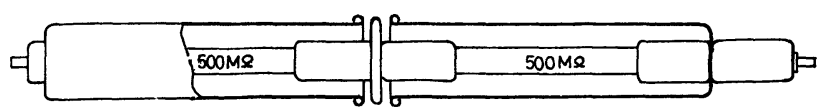

FIG. 4. - Dividing resistors and protecting annular spark gaps.

We use the carbon resistor, in which a graphite compound filament is wound in spiral on the porcelain rod. Other types of resistors, including some metallic oxide layer, have been tested, but none of them could survive a violent test in which several hundreds $\mathrm{kV}$ impulses were applied. When the carbon resistors of the above-mentioned type were used in the tandem with the above-mentioned type of protection, it was found that the resistors used for the accelerator tube have never got the damage but for the column sometimes damage occurs. The cause of damage was found due to a spark trace penetrating the porcelain base material to the axial direction. The porcelain rod was cracked by the thermal stress and then carbon filament was broken mechanically.

The penetration of the discharge trace through the insulating material has occurred in several pieces of the porcelain disks used in the column support posts in spite of the fact that the insulator posts are very well protected by the annular spark gap. Appearance of the discharge traces indicates a gradual growth of these traces (tree discharge). The penetration of these discharge traces was connected to the mechanical break of the surface glaze layer. This type of failure is probably ascribed to the original existence of voids in the porcelain material.

At present the terminal voltage is limited by this type of failure in the insulator support posts. The porcelain disks should be changed with those of high-quality material at some early time. In conclusion, the electrostatic design of the tandem accelerator seems to be satisfactory but a large mistake was made in the selection of insulator materials in some components.

5. New developments on the pellet chain. - We have long operated pellet chains of our own design in the $6 \mathrm{MV}$ Van-de-Graaff generator $[2,3]$. Their superior performance have been already mentioned in the last conference. However, the construction of these chains was not final. In order to get more ruggedness many improvements have been made on the fabrication method within the last few years. Figure 5 shows the construction of a new pellet chain. Pellets made of

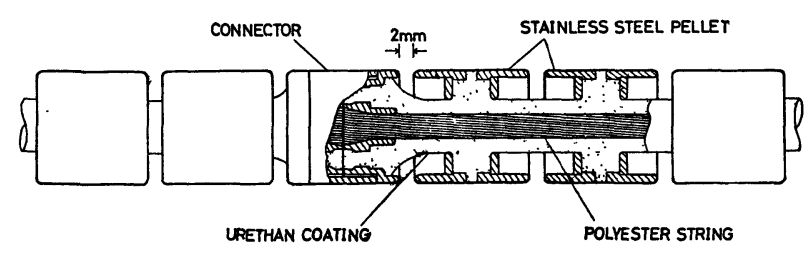

FIG. 5. - Pellet chains.

stainless steel are clamped to an insulator cord which is made by coating a polyester fiber string with thermoplastic poly-urethane. The cord is made by an extrusion molding method which is used to fabricate plastic-coated electric wires in industry. Clamping of the pellets on the cord is made by injecting fused poly-urethane into a cavity of each pellet. Important requirements for the stable operation of the pellet chain are the smallness of the degree of elongation of the cord by tensile force and the uniformity of elongation along the chain loop. A connecting way of the pellet chain to form an endless loop is shown in figure 5 , which gave a satisfactory result. 
The driving mechanism and the induction charging device are the same as shown in the last conference. So far chains of $12 \mathrm{~mm}$ diameter pellets have been used in the tandem. This chain can be driven stably enough at a running speed of $15 \mathrm{~m} / \mathrm{s}$ in the atmosphere of $10 \mathrm{~kg} / \mathrm{cm}^{2} \mathrm{SF}_{6}$ with a tension force of about $20 \mathrm{~kg}$. High pressure insulation gas effects a good damping for the vibration of the chain. An intermediate guide pulley made of poly-urethane is used in the middle portion of the $5.3 \mathrm{~m}$ horizontal column. The maximum current carried by a chain loop is about $80 \mu \mathrm{A}$, when both sides of a chain carry the charge. With larger current, instability of the lateral vibration rises up. The present tandem accelerator is equipped with four chains in the low-energy column. So the current capacity of the present pellet chain system is about $300 \mu \mathrm{A}$. This value can be increased twice by setting the same system in the high-energy column, if necessary.

In the test machine a terminal voltage of $1 \mathrm{MV}$ could be generated by using pellet chains of a similar construction under the high gradient condition of $1 \mathrm{MV} / 30 \mathrm{~cm}$. In this case $2 \mathrm{~mm}$ gaps between the pellets sustain $47 \mathrm{kV}$ in average in the atmosphere of $10 \mathrm{~kg} / \mathrm{cm}^{2} \mathrm{SF}_{6}$ gas. This gap sparks at the voltage of above $80 \mathrm{kV}$. The insulator cord is completely protected from the spark when it runs along the pellet chain. The resistance of insulator cord between the pellets is of the order of $5 \times 10^{12} \Omega$. This value does not changed appreciably even after one hundred of sparks passed along the chain. In the actual use at the tandem the voltage on the above gap is only $28 \mathrm{kV}$. Sometimes during the operation small spark light occurs at random in many gaps along the chain, due to dust or contamination in the gaps, without inducing a breakdown along the chain. Its frequency reduces gradually in a long run of operation.

Care is necessary for the poly-urethane cord to be protected from humidity. Resistance between the pellets is easily reduced by absorbing water and then the spark is induced along the pellet chain. The pellet chains of the new design increases the mechanical strength enormously so that wearing trouble of the insulator cord, inherent in the chains of the old design, has disappeared.

6. Accelerator tube. - A magnetically surpressed accelerator tube has been long operated successfully in the $6 \mathrm{MV}$ Van-de-Graaff generator of our laboratory $[1,2]$. No sign of deterioration has been observed through the operation of more than 10 thousands hours except for the leakage trouble. X-rays from the electron loading are not observed up to nearly the highest voltage of $6 \mathrm{MV}$.

Basing on this experience, advantage of the magnetic suppression was taken into the tandem tube, too (see Fig. 6). This should be very effective for heavy ion beams which are apt to produce secondary electrons along the beam trajectory. Ring magnets are set in a low electric field at the flange section of each tube unit in conjunction with a diaphragm with a small aperture $(3 \mathrm{~cm}$ in diameter). The strength of magnetic field is strong enough (300 gauss) to deflect the electrons, passing through the aperture with an energy corresponding to the maximum voltage on one tube unit $(500 \mathrm{kV})$, away from the center beam course. Most of positive or negative ions ejected from the diaphragm are deflected by the distorted electric field. Thus the ion exchange loading between the electrodes is confined within one unit of the tube. Further, in order to exterminate the cause of this process, the whole tube was constructed as a hard vacuum system, made by metal bonding of ceramic rings and metal electrodes. The tube is evacuated down to the order of $1 \times 10^{-8}$ torr by sputter ion pumps, which are placed at both ends of the tube at ground potential, the center terminal, and the middle of the tubes.
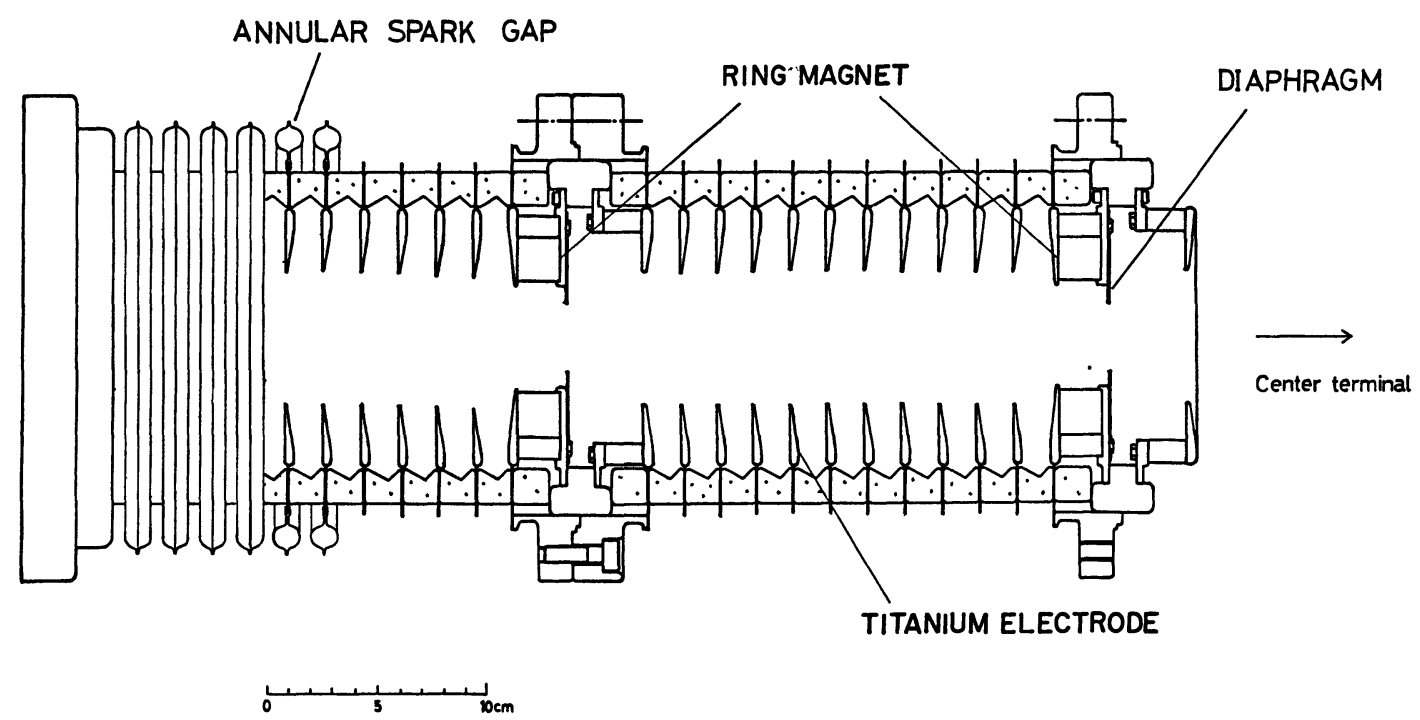

FIG. 6. - Magnetically supressed accelerator tube. 
For getting enough security of the tube from damage by the spark along the inner surface of the ceramic rings, the surface is shaped in a depressed way, as shown in figure 6. This reduces greatly the field strength at the corner of insulator-to-metal junction which becomes often a source of discharge trouble along the insulator surface. Further a rising part of the periphery of disk electrodes gives a good shielding effect for this corner.

Figure 7 shows results of the test which was made to determine the optimum configuration of insulator and electrode. The insulator ring of the depressed

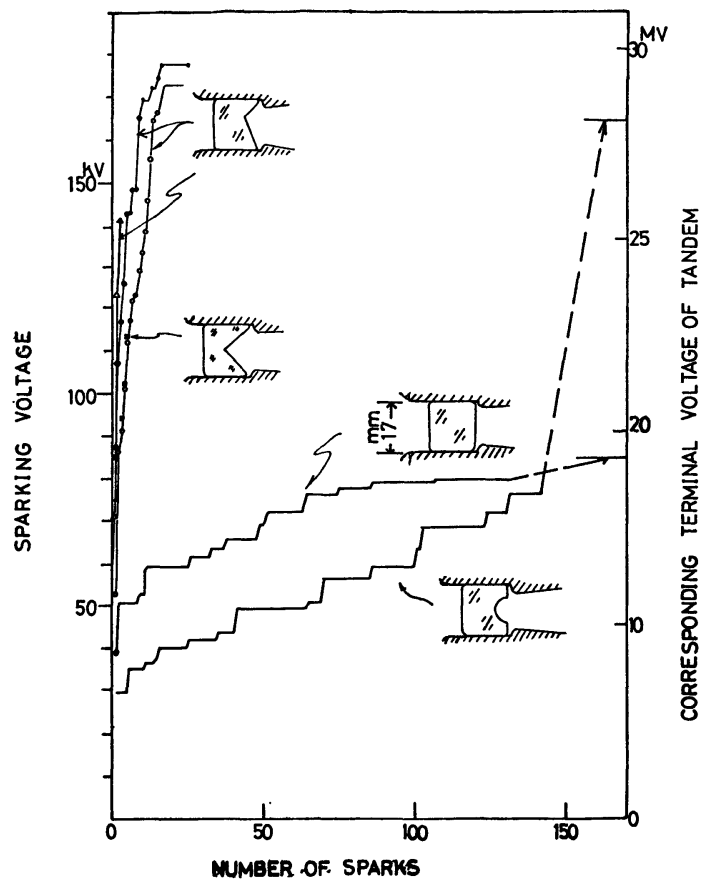

FIG. 7. - Conditioning curves for the ceramic insulator rings with various shapes of the inner surface.

shape is found to hold two times higher voltage than that of a simple cylindrical shape. This test indicated that two types of discharge traces are marked on the insulator surface; one is due to the electron cascade, occurring only on the inclined surface of the anode side and another is the streamer-like discharge, crossing the whole gap between both electrodes. The former is spread uniformly on the surface and seems to be associated with conditioning of the insulator surface. The latter is caused by some defects at the junction corner and often produces sputtering of the metal electrode at both ends of the trace. This is connected to the irrecoverable damage of insulation.

Figure 8 shows results of breakdown test made on single units of the accelerator tube. In this test it was found that (1) the only source of breakdown of the tube is spark discharge along the insulator surface, (2) the first spark takes place at about $500 \mathrm{kV}$, corresponding to $10 \mathrm{MV}$ of the tandem, (3) the tube can be promptly conditioned up to the voltage $50 \%$ higher than the above mentioned voltage after a few sparks, but severe limitation occurs much below $1 \mathrm{MV}$, (4) an irrecoverable damage is brought about by the production of spark traces on the insulator surface and the contamination by sputtered electrode metal, being accompanied with the production of strong X-rays.

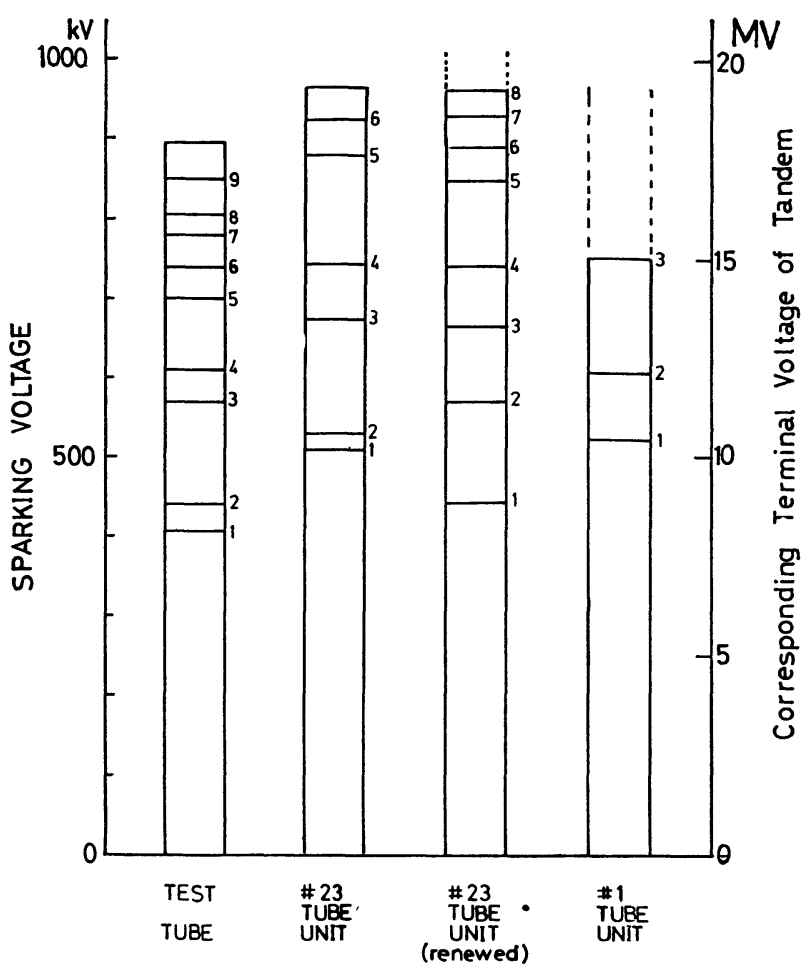

FIG. 8. - Conditioning of single units of the accelerator tube.

In the actual operation of the above accelerator tube, mounted on the tandem, the situation was quite different from that observed in the test for the single units. Here the all discharge events in the tube developed into a glow discharge accompanying severe outgas, owing to a very slow pumping speed through the tube aperture. It was found that the normal conditioning process was too slow for degassing, probably owing to the fact that the tube is designed such that the quenching mechanism works very strongly. Several methods promoting the conditioning are now being tested.

7. Provisions for high energy injection of the negative ion beam. - Since the high injection voltage simplifies greatly the problem of the ion optics in the accelerator tube, we planned to use a rather high voltage for pre-acceleration. High injection voltage is also desirable for heavy ions by the reason that the collision cross section becomes smaller and for protons by the reason that the deflection of the beam path by the quenching magnets is smaller. As a high voltage source for the pre-acceleration up to $300 \mathrm{kV}$ a small electrostatic generator has been made. Here instead of the pellet chains, an insulator rotating disk with pellets on periphery is used. The rotation 
velocity is $3600 \mathrm{rev} . / \mathrm{min}$. Corona needles are used for transferring charge to and from the pellets. The whole system is included in a large porcelain bushing, filled with a high pressure $\mathrm{SF}_{6}$ gas. The current capa- city is about $200 \mu \mathrm{A}$. This type of high voltage DC generator is suited for use with the injection system of the tandem, where the required voltage is very high but the current is small.

\section{References}

[1] Isoya A., Proc. Int. Conf. on the Technology of Electrostatic Accelerators (Daresbury) 1973, p. 89, 233, 314.

[2] Isoya A. et al., Mem. Sci. Kyushu Univ., Ser. B, Phys. 4 (1970) Special issue.

[3] Isoya A. and Nakashima, T., Nucl. Instrum. and Meth. 88 (1970) 33. 